\title{
"My Voice is who I am" - Vocal Improvisation Group Work with Healthy Community-Dwelling Older Adults
}

\author{
Aviya Riabzev ${ }^{1 *}$, Ayelet Dassa ${ }^{1}$, Ehud Bodner ${ }^{1}$ \\ 1 Bar-Ilan University, Israel \\ *aviyak@gmail.com \\ Received: 2 September 2020 Accepted: 14 October 2021 Published: 1 March 2022 \\ Editor: Helen Brenda Oosthuizen Reviewers: Zara Thompson, Kendra Ray
}

\begin{abstract}
Background: Vocal improvisation is known as beneficial in promoting well-being, yet not much is known about using vocal improvisation with healthy older adults. While the emphasis in music therapy on studying interventions with clinical populations of older adults is important, the challenges and stressors facing healthy older adults require more investigation.

Methods: This qualitative study analyzed the experiences of 54 older adults, ranging between 60 and 93 years $(M=71.07)$, who participated in 12 weekly vocal improvisation group meetings that incorporated various voice improvisation techniques. Data was gathered using qualitative semi-structured group interviews with 12 focus groups (pre- and post-intervention).

Results: A qualitative content analysis revealed that the vocal improvisations created the sense of an open space where participants could express and explore their own voices. The intervention has changed their attitudes regarding their own voices and led to meaningful personal experiences and new self-discoveries. The participants described experiencing a significant emotional process during the group work and reported experiencing self-exploration, and improvements in their self-beliefs, attitudes regarding their own voices, and their well-being.

Conclusions: Vocal improvisation group intervention was experienced as beneficial for the well-being of healthy community-dwelling older adults.
\end{abstract}

Keywords: community-dwelling, older adults, music therapy, vocal improvisation, well-being

\section{Introduction}

In recent years, the population of older adults has increased worldwide (World Health Organization ([WHO], 2017). Older adults are subjected to numerous challenges, such as decreased physical and cognitive functioning, changes to their economic and professional status, and a reduction in their support systems due to the death of family members and friends (Courtin \& Knapp, 2017; WHO, 2017). Such losses may lead to 
decreased self-esteem and to lowered sense of security, and even to social and professional withdrawal, loneliness, and subclinical depression (Chiang et al., 2010; Courtin \& Knapp, 2017). Therefore, in this study we focus on such normative older adults who do not present any specific form of psychopathology. Our clinical stance is in accordance with the WHO's definition of health (2017) as a state of complete physical, mental, and social well-being, and not only as the absence of disease (WHO, 2017). This line of thought also corresponds with the salutogenic approach and the school of positive psychology which are focusing on mental health promotion, prevention and rehabilitation (Antonovsky, 1996; Kobau et al., 2011).

Moreover, upon observing the stressors which older adults have to cope, ageism may also affect their well-being. The social phenomenon of ageism includes self-age stereotypes which are directed by older adults toward their own age-group (Levy, 2009). These self-stereotypes cause them to perceive themselves as weak, dependent, and socially insignificant (Ayalon \& Tesch-Römer, 2017; Bodner, 2009).

The negative effects that aging stereotypes have on older adults' physical and mental functioning emphasize the need to mitigate such stereotypes (Coffman, 2002; Patel et al., 2011). Therefore, group program interventions for community-dwelling older adults such as intergenerational performing arts interventions (e.g., participating in an intergenerational theatre group) aim to increase the knowledge about the negative effect of ageism on older adults. These program interventions also help to decrease ageist stereotypes, and have been found to be successful in increasing positive age stereotypes and reducing negative age stereotypes. Moreover, they improve well-being among community-dwelling older adults by building social networks, confidence, and self-esteem (Anderson et al., 2017; Ermer et al., 2021).

Encouraged by these programs, the current group which focused on free vocal improvisation expression was aimed to unleash inhibitions that people have regarding their voices (Austin, 2009), and thereby not only improve older adults' self-expressions, but also enhance their self-confidence and self-esteem. Following Austin (2009), we believed that conducting a free vocal improvisation with independent older adults, who are living at their own homes, would help to strengthen positive self-attitudes and improve their well-being.

In this regard, previous studies have also indicated that music plays a significant and essential role as it helps to maintain a sense of personal and social identity in old age (DeNora, 2000; Gabrielsson, 2002; MacDonald et al., 2002). Furthermore, music can evoke self-reflections of personal life events, illuminate hidden aspects of one's personality, and revive hidden emotions through reminiscing (Clements-Cortés, 2017; Creech et al., 2013; Dassa, 2018). However, the literature regarding group interventions with community-dwelling older adults is only comprised of studies on choirs and on community singing activities, and none on vocal improvisations with older adults (Cohen et al., 2007; Hays \& Minichiello, 2005). Clinical studies on vocal improvisation focus primarily on individual work and address populations in crises such as people dealing with post-trauma, cancer, or age-related illnesses (Austin, 2002, 2009; Baker \& Uhlig, 2011; Newham, 1998). These studies indicate that music interventions with older adults enable the creation of an intimate, safe, and reliable musical environment that reduces negative emotions, enhances feelings of mental well-being, satisfaction and hope, and yields a sense of success (Adler et al., 2012; Austin, 2001, 2002, 2009; Baker \& Uhlig, 2011).

Choirs and community singing were found to be efficient in promoting emotional regulation, and in increasing social interactions and older adults' subjective and psychological well-being (Mohammadi et al., 2011; Noice et al., 2013; Skingley et al., 2011). Moreover, singing in a choir had a stimulating effect on older adults' motivation, involvement, and interest in life, as it increased their sense of self-confidence and capability, and happiness. This could be due to an increase in their confidence to sing in a clear and free manner and to experience their presence by using their own voice (Clair \& Memmott, 2008; Hays \& Minichiello, 2005; Noice et al., 2013). In this regard it was also found that older adults who participated in a music-therapist led choir and 
thereby experienced their voice being heard expressively, exhibited an improvement in their quality of life and reduced depressive symptoms compared to a control group that received standard care (Ahessy, 2016; Zanini \& Leao, 2006).

The positive effects of group vocal activities on the health of community-dwelling older adults were also evidenced on a biological level. Studies have demonstrated that group vocal activities may balance the natural decline in voice control mechanisms, known as presbyphonia, which occurs in old age. Presbyphonia occurs as a result of structural changes in the larynx, which is evident in people after the age of sixty (Marchand \& Bonamigo, 2015). Studies have shown that participating in a choir maintains muscle tone, increases cardiovascular strength, improves respiratory functioning, and even prevents cognitive decline. It was demonstrated that older adults who participate in choirs report an improvement in their health, report fewer visits to the doctor's office, and show a reduction in the consumption of over-the-counter drugs (Cohen et al., 2007; Tamplin et al., 2013).

While the abovementioned studies provide solid evidence about the importance of group singing for older adults, vocal improvisational group work is different from group singing and may add value in many other aspects. These include:

1. Participating in vocal workshops requires no training as they are not focusing on sounding "good" but are geared toward having fun and entering unexplored territories, with the attitude that all people can make sounds (Austin, 2009).

2. Vocal workshops and vocal group interventions assist participants to reduce their anxiety levels through using breathing exercises, followed by relaxation that is experienced as acting on deeper bodily sensations (Austin, 2001, 2009; Baker \& Uhlig, 2011; MacIntosh, 2003; Zarate, 2016).

3. Vocal workshops help in promoting a sense of playful space which allows an experience of the "here and now" (Austin, 2009).

4. Vocal workshops increase spontaneity, decrease fears and increase creativity (Adler et al., 2012; Austin, 2009; Baker \& Uhlig, 2011).

5. Vocal workshops enhance the recognition and the expression of feelings and needs (Adler et al., 2012; Austin, 2009; Baker \& Uhlig, 2011).

6. Vocal workshops enable an intimate, reliable, and safe musical environment in which unconscious feelings, sensations, memories, and associations can be accessed, processed, and integrated (Adler et al., 2012; Austin, 2001, 2002, 2009).

Studies exploring vocal therapy tend to focus on individual therapeutic interventions with people in crisis such as those with post-trauma, cancer, or age-related diseases. These studies mostly indicate that vocal improvisation may help deal with physical and psychological limitations, and promote well-being (Adler et al., 2012; Baker \& Uhlig, 2011; MacIntosh, 2003; Newham, 1998). In spite of the many advantages of vocal improvisation work, to the best of our knowledge, none of the above studies examined vocal improvisation group work for healthy older adults.

With the aim of exploring the added value of group vocal improvisation as a beneficial intervention in music therapy with older adults, the current study followed a vocal improvisation therapy with a group of healthy older adults, living in their communities. This study examined whether such intervention promotes their sense of self, improves their self-perceptions, and frees them from inhibitions regarding their voice.

\section{Method}

This qualitative research is part of a $\mathrm{PhD}$ project that included a quantitative study, which also focused on the quantitative aspects of self-perceptions of aging and subjective well-being as measured by self-report questionnaires among community-dwelling older adults. In addition to the quantitative data, we included semi-structured interviews in a focus-group format, during the first and last session of each group. 
Due to the immensity of material gathered in this research (such as/including questionnaires delivered to each group throughout an 8-month period on five different occasions), this study focuses on the qualitative findings from the focus groups. As this is an ongoing project that collects much data, other parts of this project are intended to be written for separate future publications.

It should also be noted that the participants signed an informed consent form and provided their permission to include the contents of the conversations in this study. Names have been replaced by pseudonyms in this manuscript. All other data concerning personal information was concealed. This research received ethical approval from Bar-Ilan University (Approval no. E.MUS. 21.5.2017).

\section{Participants}

The 54 participants in the program resided in the community and were considered "healthy" as reported by self-administered questionnaires. Based on these questionnaires, inclusion criteria were a health condition without a self-reported diagnosis of chronic diseases, psychiatric issues, or a cognitive or functional decline. Participants included 48 women and 7 men (ages ranged from 60-93; mean age 71.07). The participants were recruited from social clubs for older adults and attended the meetings independently. Most of them were women (87\%), with high school or academic education (82.6\%), most reported as having a good health condition $(77.2 \%)$, as financially well off (93.3\%), and with no previous musical background (92.5\%).

\section{Session Format}

Following a pilot group facilitated by the first author (a music therapist), which included five sessions conducted once a week with 10 community-dwelling older adults, a preliminary protocol was formatted. The protocol was based on two senior music therapists' clinical experience in conducting music therapy groups with adults. Based on the positive findings of the pilot, including improvement in self-efficacy, self-esteem, and in mental well-being measures, an intervention led by the same protocol was delivered to the 54 participants mentioned above. The protocol included 12 weekly continuous sessions for three-months.

Each session lasted 90 minutes. There were six intervention groups, each containing 8-10 participants (54 participants in total). Two music therapists co-conducted each of the six groups, which took place at the first author's university. The music therapists attended weekly supervision meetings with a professional music therapist throughout the intervention.

The format and musical material were pre-planned according to the participants' musical preferences, which were elicited during the pre-focused group interview. Each session included the following activities:

- Personal name circle improvisation - Each session began with the participants improvising a melody and with each of them singing his/her name.

- Physical and vocal exercises - Warm-up body exercises were utilized in order to enhance vocal expression. The therapists combined the physical exercises with breathing exercises and vocal expression exercises. The vocal exercises contained syllable exercises (such as $A, E, I, O, U$ ); vocal dynamic exercises while walking in the room (such as singing forte or piano); vocal pedagogy exercises using singing techniques, such as vocal production techniques; techniques for extending the vocal range; and resonance techniques, such as vocal registers (head register for the flute configuration, chest register for the clarinet configuration, and stomach register for the saxophone configuration). We believed that each configuration could help the older adults explore different qualities in their voices and express different kinds of emotions. Using the flute configuration, we could see that the participants used their high larynx in the neck, creating a short tube and closing the vocal cords. We expected that as a result, their solid emotional 
sensations would grow weaker, and that they will be able to experience more of their stoic and frosty feelings and a stronger mental control. Using the clarinet configuration, we hoped that the participants will use their lower position of the larynx in the neck, creating a longer tube, thereby enabling them to experience their primary emotions attributed to the heart, such as love, courage, romance, and sympathy. Finally, by using the saxophone configuration, we aimed that the participants will use a complete descent of their larynx in the neck, creating a long tube, which might enable them to experience their deep and core feelings such as grief, fear, and happiness (Newham, 1998).

- Vocal improvisation exercises - These exercises were mostly performed in a group format, in couples, or in trios. Some of the exercises created an atmosphere of fun, joy, and laughter, such as the "gibberish" game, where the participants were arranged in pairs who communicated improvised inexplicable syllables and sounds. Other exercises created a calm atmosphere. For example, an exercise termed "vocal bath," in which all the participants vocally improvised while standing in a circle, and each participant entered the circle in turn, to "bathe in the sounds" of their friends. Then they could choose to listen or improvise, or even to lead the melodic improvisation. These exercises were constructed in order to enable the participants to reflect and express themselves spontaneously. While the participants improvised vocally, the therapists used vocal grounding (Austin, 2001) for support and encouragement, aimed at creating a safe environment.

- Composing songs - Experiencing vocal improvisation exercises during the workshop enabled the participants not only to write new lyrics for well-known songs from their past, but as they learned how to improvise (mid-workshop, around the sixth session), they even started to compose their own songs, including lyrics and melody.

- Closure - The participants sang the sound homm together at the same pitch. Each participant who wanted to improvise could leave the homm tune while improvising their own melody, and then return to the group's homm.

- Closing discussion - Following each session, the participants conducted a discussion in which they reviewed their experiences during the session and suggested activities for the next session. In this regard, the topics and content for the next meeting were mainly chosen from the ideas and wishes the participants raised throughout the session.

\section{Data Collection and Analysis}

There were six pre- and post- intervention focus groups (FG). Each included 8-10 participants. The focus group interviews were conducted by the music therapists who cofacilitated the intervention. Focus group data allow rich information to emerge from the interaction between participants during the discussion. The researcher encourages participants to share their thoughts and respond to other members in the group (Acocella, 2012).

The discussion in the focus groups included questions such as:

- What were the primary expectations and reasons for joining the group?

- Were there any useful tools learned during the workshop?

- What were the advantages and disadvantages of the group work?

- How did you feel about your own voice?

These questions helped to promote a group discussion. While the music therapists were often not required to intervene, they tried to encourage all group members to engage. Qualitative content analysis revealed that group members engaged in an open dialogue and that the therapists had very few interventions in this dialogue.

The data was analyzed through a systematic qualitative content analysis (Kohlbacher, 2005) collected from the six groups on two occasions: pre-intervention (session 
number 1), and post-intervention (session number 12). A systematic process of stepby-step categorization was conducted. During the initial coding stage, the researchers marked word fragments, lines, segments, and incidents of the participants' experiences. The researchers aimed to remain open to all possible directions indicated by the data. In the second coding stage, these textual parts were conceptualized into more salient categories, using the most common codes which were previously marked during the initial stage, with the aim of condensing the previous codes into general categories. This systematic process enabled us to focus on the main themes concerning the participants' attitudes and feelings regarding the vocal group experience.

The music therapists who guided the intervention also conducted the focus groups. One of the music therapists was also the researcher (the first author). These dual roles created more concerns regarding the aims of the intervention and its efficiency according to the expected results of the research and according to the opened responses of the participants. The dual expectations as a researcher and as a therapist were managed by receiving thorough supervision from an experienced music therapist throughout the intervention, striving to separate these potentially conflicting roles by focusing on the aims of the group itself and not on the expectations of the research (Bourdeau, 2000; Conneeley, 2002). Moreover, for the sake of credibility, and due to "the challenges of dealing with the researchers' preconditions and consequences of research focusing on (social) critique, usefulness, relevance and ethics" (Stige et al., 2009, p. 1504), an experienced music therapist with expertise in working with older adults served as an external examiner, reviewed $80 \%$ of the data and commented on the reports from the content analysis.

\section{Results}

Based on the analysis, three main categories emerged. The vocal improvisation group intervention: (1) created an open space for freeing and exploring one's voice; (2) changed the participants' attitudes regarding their own voices; and (3) led to meaningful experiences and new self-discoveries. In the following sections, we elaborate on each finding.

\section{The vocal improvisation group intervention created an open space for freeing and exploring one's voice.}

At the beginning of the workshop, some participants expressed their desire to free their voice, stating that something is blocking it. The main reasons for this blockage, described by the participants, were self-criticism, cultural boundaries, and lack of support from relatives:

There are many conventions regarding how we should behave or speak. We didn't allow ourselves all those years [...] I want to give myself here the freedom to shout and do things that were not acceptable as a good girl [...] to use my voice in an unusual and non-judgmental way." (Ilana, pre-intervention focus group 1 [pre-FG1])

I want a way to express myself through voice. There are various ways to express ourselves, and we don't always use vocal expression. Sometimes it is also repressed emotions. I want to give everything a voice. (Keren, pre-FG5)

After experiencing vocal improvisations, the participants stated that thanks to the workshop they received legitimacy to use their voice freely:

First of all, it helped us express ourselves, remove obstacles, barriers [...] it's like opening doors that were closed before. I feel free. (Zvika, post-FG4)

I really like to sing, but I don't yet have the ability to stay in tune, but here it is possible

[...] here you are allowed to be out of tune with pleasure! (Rachel, post-FG2) 


\section{The vocal improvisation group intervention changed the participants' atti- tudes regarding their own voices.}

At the beginning of the workshop, the participants said that although the voice is a tool for expression, they cannot express themselves as they would like to through their voice and as they did in the past:

My voice - I would like it to be stronger, it's a little weak. It's about the ability of expression. My voice is not what it was. It's not the same. (Betty, pre-FG2)

In addition to their dissatisfaction with their voices, the participants also expressed a desire to change their voices because they were uncomfortable with them:

I do not feel good about my voice. People think that because I speak quietly, I'm hesitant about what I'm saying, but it's not true. I used to talk politely [...] I would like to improve it [my voice]...maybe I can increase my vocal range. (Oren, pre-FG1)

More strongly, Shula declared:

I have a defect in my voice, I hate my voice! (Shula, pre-FG3)

By the end of the meetings, Shula's attitude changed dramatically:

I've got this issue with my voice. Everyone thinks I have a man's voice because I have a low voice, but here I am sitting in the workshop next to Rina, and her voice is as low as a man's voice, even lower than mine, but she is a singer, she has a nice voice. So, if I have a low voice it doesn't mean I have an ugly voice. I do not hate my voice anymore. (Shula, post-FG3)

These new experiences helped them to develop a new positive perspective on their voice and to feel more comfortable about expressing themselves using their voices. Hanna shared with the group that for the first time during a family gathering in which she usually let her husband do the talking, she allowed herself to speak:

I found that I was able and capable [...] I can express myself! [...] Thanks to the workshop I took the initiative [...] I allowed myself. I had the opportunity to get the best out of myself [...] I think they [my family] were shocked. (Hanna, post-FG1)

Carmen also revealed that she could now feel free to express herself:

In our generation, we had to listen to our parents. We never spoke or said what we wanted. Not expressing myself was as if I didn't exist. Now I can say what I want, something opened up inside me, and helped me to express myself. (Carmen, post-FG6)

\section{The vocal improvisation group intervention led to meaningful experiences and new self-discoveries.}

At the beginning of the workshop the participants discussed the connection between their voices and their emotional and mental states:

I believe that there is a solid connection between voice and mental state [...]. Voice, feelings, and the soul are all connected! (Betty, pre-FG3)

Dana wanted to understand and discover new things about herself:

What fascinates me is the whole idea of improvisation... It will reveal all kinds of things that you do not think about yourself [...]. You're the most authentic when you act spontaneously without planning. (Dana, pre-FG1)

The spontaneous and improvisational use of their voice brought with it unconscious elements from their distant past. This phenomenon can be captured by describing Shimon, an 86-year-old participant, characterized by his bent head posture. In one of the sessions, Shimon sang prayers and cantillations from his father's home, which he had not sung for more than 70 years. While Shimon was singing, he stood and straightened 
up. That was the first time that the group members and the music therapists saw him standing upright and with his head held high. During the discussion, which took place in the final session, Shimon talked about this powerful experience:

I sang while praying here. I hadn't done it for 80 years. What made me do this? Something came out of me [...]. There are many things that we are not aware of at all that came out... and that caused happiness ... I have opened up beautifully. Who would have believed that I straightened up and stood upright? That is, things that you are not aware of happen to you. (Shimon, post-FG5)

Self-discoveries were revealed in the concluding focus group. Paula realized how she communicated with people in the group. She shared this with the participants:

It also helped me to understand that I was a bit bossy, and I tried to enforce myself. [ ... ] I noticed that my voice was too dominant and realized that other people also have something to say and contribute. It was a sudden realization, and it was in this small group, that on the one hand, it was hard for me to admit that this is me, but on the other hand, I promised myself I would hold back more. (Paula, post-FG4)

Naama shared her insights following her exploration through voice work:

My voice is not just part of my body and a tool for communicating, but is a part of my body, a part of my soul [...] What is my voice? Who am I? What am I? [...] My voice is my place in the world. My voice is a part of my being. (Naama, post-FG3)

The concluding song written by the group's members (group number 5) gives voice to these meaningful experiences:

In the voice improvisation sessions,

Voices and sounds from the mouth are playing

Laughter and tears accompanied our working

Animal voices here we are imitating

We are breaking through the glass ceiling.

In this song, the participants recount how the voices and sounds they made created a new mode of expression and led to self-discoveries. Shimon, the participant who experienced such intense feelings, wrote the last line of this song - We are breaking through the glass ceiling. In this line, Shimon meant that during the intervention, he reached new heights of emotional, mental, and physical expression that he did not believe he could experience.

\section{Discussion}

\section{The Uniqueness of the Study and Major Findings}

To the authors' knowledge, this is the only published study that uses vocal group improvisation in healthy older adults as a means to change their views on their voices and thereby to improve their self-esteem. As previously reviewed in the introduction, studies in this field mostly focused on populations of older adults with medical and psychiatric problems. The findings of this research indeed demonstrated that the participants experienced a significant and a positive emotional process due to the group work. This process began by them playing an active role in a new experience that has led them to improve their attitude about their voices. Moreover, the participants were involved in self-exploration and reported an improvement in their self-beliefs concerning their voice and interpersonal capabilities, as well as an observable positive change in behaviors in the group, such as self-expression and in regard to reported behaviors like the initiation of new activities in their daily lives.

\section{The Effect of Vocal Improvisation on Self-perceptions and Emotions}

Exploring their voice through vocal improvisational group work introduced the participants to a new experimental activity, one that helped them to free inner boundaries 
and discover new modes of expression. Their vocal exploration has led them to an intimate experience. The music therapists provided vocal means for exploring sounds and aimed to improve their capacity to release sounds and primitive vocal expressions, helping them to reconnect with their primal nature, access intense feelings, and give voice to the inexpressible and to their entire range of personality (Loewy, 2004). In this respect, this vocal exploration helped the participants express themselves, but also voiced emotions and feelings that were out of their awareness.

\section{Possible Mechanisms by which Vocal Improvisation Improves Self- perceptions and Emotions}

The mechanisms by which the vocal improvisation has served as an outlet for these emotions, validated them, and provided them with new meaning can be deduced from the participants' reports. The participants reported feeling understood by the other group members and the therapists. They said that vocalizing and improvising together was meaningful, and made them feel more secure and a greater sense of belonging than before their participation. This is in line with previous clinical evidence demonstrating that exploring and voicing repressed primitive sound forms of self-expression (screams, sobs, etc.) helped to reclaim aspects of people that have been silenced or inhibited by their families and society (Loewy, 2004). This evidence is also consistent with the participants' experience regarding cultural influences which characterize people of their generation in which it was common to be silenced. Some of them reported that from childhood and throughout most of their adulthood they had to internalize their wishes, desires, and feelings. Due to their old age, the participants reported that they gave up any hope they would ever express those repressed feelings. Not being able to express oneself as a child might lead to repressed feelings, insecurity, and anxiety in adulthood. Someone who has been silenced in the past might not even recognize or understand these negative feelings and how they are related to the current wish for self-expression (O'Loughlin, 1995).

Producing sounds and exploring one's voice play a larger role than just freeing hidden emotions. It is the key to accepting one's voice regardless of training or background (Oddy, 2011). Therefore, perhaps using their voice as a channel for emotional expression helped the participants not just to accept their voice as it is, but also to accept themselves.

Another possible explanation for the evident change in the participants' self-acceptance was the impact of vocal expression as a physical experience. Finnegan (2012) has argued that music is experienced directly in and through the body, as it enhances one's sense of self and better familiarizes a person with their own personality. Moreover, Bojner-Horwitz (2018) argued that music also increases contact with embedded emotions and develops empathy. A renewed contact with the self and an improved mood can change a person's perception and, consequently, their well-being (Robertson \& Monaghan, 2012; Seidler, 2007).

Vocal improvisation can also serve as an outlet for experiencing a wide range of emotions. The participants reported that improvising together led them to experiencing and expressing contradictory emotions. Music engagement offers what Seidler (2007) refers to as an "emotional space," where it is socially accepted to experience a wide range of different emotional and affective states. Moreover, a vocal improvisation group work might aid in reinforcing the capacity to differentiate between positive and negative feelings. In some vocal exercises the participants testified that they not only learned how to express emotions in general but also to express contradictory emotions. This is notable due to cultural influences which characterize their older generation. Through vocal improvisational group work they expressed feelings that were sometimes contradictory (such as joy and sadness, etc.). Thus, as Ong and Bergeman (2004) argued, the participants reinforced their capacity for emotional complexity, which seems to improve in later life (Bodner et al., 2012; Carstensen et al., 2000; 
Ready et al., 2006; Ready et al., 2008). As the group provided a safe space for the participants to vocally express their emotions, it enabled them to use this ability.

\section{The Vocal Improvisation Group as a Safe Place}

From childhood, the self-perception of one's voice is strongly connected to others' opinions, which is why vocal exploration requires safe and non-judgmental environments. A safe environment makes it possible to share private experiences and serves as a venue for personal discoveries (Loewy, 2004). Indeed, the participants in this study reported that they experienced the group as a safe place.

In this regard, the term a "field of play," coined by Kenny (2014), can be used. A field of play is a musical space where one feels secure and is free to engage in play. It is a space where there is a new openness, freedom, and a joyful sense of discovery, experimentation, and energy. According to this term, in one's playfulness one may find authenticity, innovation, enjoyment, pleasure, and joy (Kenny, 2014). As can be seen from the qualitative data, the participants shared the notion that the group served as a safe and containing place for expressing their emotions. Some participants even testified that the group has inspired them with such a sense of confidence in expressing their feelings they had never evidenced before. They also reported that the atmosphere of the group enabled them: to feel free to play with their bodies and voices; to openly express various types of vocal expressions, such as a child's voice or an authoritative voice; and to express their thoughts. The participants testified that this new experience enabled them later to transform this reassuring and safe atmosphere to their play with their grandchildren.

It should be noted that at the same time, they also expressed some reservation, stating that the outside world (their family members), might judge their behavior as unsuitable for their old age. The positive atmosphere had evolved through the workshop and enabled the participants to experience the "field of play." They explored new ways of expression, released repressed emotions, and freed themselves from their old beliefs by exploring new territories. They no longer felt that their voices are ugly and expressed the feeling that they are capable and allowed to play despite their old age.

This finally led them to change their beliefs and behaviors and to more strongly believe in their ability to sing in front of other people, join community choirs, write songs, and plan new activities in their daily life, such as learning new academic skills or going on vacation. In this regard we can conclude that the participants in the group had personal resources that could enable them to achieve such benefits from the vocal improvisation group, and this conclusion justifies the investment of music therapists in groups of healthy older adults.

\section{The Effect of the Group on the Participants' Self-esteem}

Self-esteem is defined by Harter (2006) as an overall feeling of self-worth, which is essential in promoting emotional well-being (Mann et al., 2004; Rogers, 1961). Feelings of self-worth can act as a psychological engine that propels us toward positive health and adaptation. Criticism, on the other hand, deeply questions our self-worth (DuBois et al., 2009).

The effect of vocal expression on the participants' self-esteem may have created a bi-directional process, whereby the vocal expression improved these self-perceptions, which subsequently enabled better vocal self-expression, and vice versa. The participants reported that they better recognized themselves: My voice is who I am (Rivka, post-FG4); and they felt more confident in managing their everyday lives. Some even reported a change in their behavior, such as initiating new things they never had the courage to do before, despite the ageist belief that "you can't teach an old dog new tricks." The safe and non-critical vocal improvisation group work enabled the participants to self-explore, make new self-discoveries and strengthened their self-esteem and well-being. 


\section{The Effect of the Group on the Participants' Sense of Meaning and Identity}

Engaging in music provides emotional rewards for people, such as being in touch with one's emotions (Juslin \& Sloboda, 2010). Being in touch with one's emotions is important since it "lies at the heart of our capacity to experience meaning" (Johnson, 2007, p. 53), and meaning is one of the central elements of well-being (Batt-Rawden et al., 2005; Ruud, 2013). As people understand, recognize and acknowledge new parts of themselves and their uniqueness, they find new meaning in their lives, which promotes positive psychological well-being (Zika \& Chamberlain, 1992), including being more adept at dealing with life's challenges (Krok, 2015; Park \& Folkman, 1997). As stated before, older adults face many challenges in their daily lives, which may evoke a mix of undefined negative emotions which may undermine their sense of meaning. As demonstrated in this study and in line with other current studies that showed the value of musical involvement in old age (e.g., Lindblad \& de Boise, 2019), the improvised vocal group work offered a variety of experiences of emotional expression that may alleviate the challenges and physical impairments that accompany the aging process and provide new meaning to the participants.

Our findings are also consistent with other studies showing that music engagement in old age reveals hidden parts of older adults' identity, provides them with a sense of meaning and stability, and strengthens their sense of self (Lindblad \& de Boise, 2019, Volgsten, 2012; Volgsten \& Pripp, 2016). The participants in this study experienced new modes of expression through vocal exploration, which helped them to discover new and dormant elements of their self-identity. This may have helped them deal with the challenges they encounter in old age, such as loss of meaning in life, social status and networks, and their sense of identity, factors that tremendously impact their wellbeing (Jackson, 2016; Russell, 2004). The vocal improvisation group provided a safe environment to explore their identities by expressing themselves vocally and improvising in the here and now freely, leaving prior self-judgments behind.

\section{Epilogue}

Everyday use of music in old age is a "provider of vitality - that is, emotional stimulation and expression; tool for developing agency and empowerment; resource in building social networks; and a way of providing meaning and coherence in life" (Ruud, 2013, p. 10). All these advantages of music engagement are in accordance with the participants' experiences regarding their new sense of capability that empowered them not only during the group work but, most importantly, in their daily lives. The participants shared their plans to join local choirs and to perform at social gatherings, they talked about new plans for vacations, reported new friendships, and even decided to register to academic programs. In addition to their change in behaviors, this emotional process via the vocal improvisation group work has led the participants to a changed attitude toward their voice, as well as to a change in their self-beliefs concerning their voice and interpersonal capabilities. As they wrote in one of their songs: We are older people, 60 years old, experiencing how to smile and how to have fun, learning how to create more fun from within ourselves, fun that until now was hidden (from concluding song, group number 2).

\section{About the Authors}

Aviya Riabzev. Music Therapist, Ph.D., Graduated Music therapy Ph.D program at Bar-Ilan University, Israel. Aviya has clinical experience working with children with autism, women coping with sexual abuse, and with older adults. Her research focuses on the impact of vocal group work on the well-being of older adults and on women coping with complex PTSD.

Ayelet Dassa. Music Therapist, Ph.D., Head of Music Therapy M.A Program at BarIlan University. Teaches in different programs of geriatric training, has been working 
with people with dementia for the past twenty years, and has experience with stroke patients, Parkinson disease and chronic psychiatric elderly. Her research focuses on the effect of music on people with dementia and their family caregivers in nursing home settings and at home.

Ehud Bodner. A full professor of psychology, the head of the Interdisciplinary Department of Social Sciences and staff member at the Department of music - at Bar Ilan University, Israel. A Clinical and a Medical Psychologist and a supervisor in both fields with vast clinical experience working with younger and older patients, suffering from various anxiety disorders, somatization, depression, and personality disorders. In the field of music he is mainly focused on emotion regulation through music in young and older adults. He also concentrates on models delineating the relationship between ageism and other perceptions of aging, personal resources and various aspects of health and mental health among older adults, and tries to uncover factors associated with end of life anxieties, and with time perceptions. His studies include longitudinal designs and diaries. Thus far he has published over 120 articles in peer-reviewed journals and 9 chapters in books.

\section{References}

Acocella, I. (2012). The focus groups in social research: Advantages and disadvantages. Quality \& Quantity, 46(4), 1125-1136. https://doi.org/10.1007/s11135-011-9600-4

Adler, R. K., Antoni, C., Hirsch, S., \& Mordaunt, M. (2012). Vocal health and phonotrauma. Plural Publishing.

Ahessy, B. (2016). The use of a music therapy choir to reduce depression and improve quality of life in older adults - A randomized control trial. Music and Medicine, 8(1), 17-28.

Anderson, S., Fast, J., Keating, N., Eales, J., Chivers, S., \& Barnet, D. (2017). Translating knowledge: Promoting health through intergenerational community arts programming. Health Promotion Practice, 18(1), 15-25.

Antonovsky, A. (1996). The salutogenic model as a theory to guide health promotion. Health Promotion International, 11(1), 11-18. https://doi.org/10.1093/heapro/11.1.11

Austin, D. (2001). In search of the self: The use of vocal holding techniques with adults traumatized as children. Music Therapy Perspectives, 19(1), 22-30. https://doi.org/10.1093/ $\mathrm{mtp} / 19.1 .22$

Austin, D. (2002). The voice of trauma: A wounded healer's perspective. In J. Sutton (Ed.), Music, music therapy, and trauma: International perspectives (pp. 231-259). Jessica Kingsley Publishers.

Austin, D. (2009). The theory and practice of vocal psychotherapy: Songs of the self. Jessica Kingsley Publishers.

Ayalon, L., \& Tesch-Römer, C. (2017). Taking a closer look at ageism: Self-and other-directed ageist attitudes and discrimination. European Journal of Ageing, 14, 1-4. https://doi.org/ 10.1007/s10433-016-0409-9

Baker, F., \& Uhlig, S. (2011). Voicework in music therapy: Research and practice. Jessica Kingsley Publishers.

Batt-Rawden, K. B., DeNora, T., \& Ruud, E. (2005). Music listening and empowerment in health promotion: A study of the role and significance of music in everyday life of the longterm ill. Nordic Journal of Music Therapy, 14(2), 120-136. https://doi.org/10.1080/ 08098130509478134

Bodner, E. (2009). On the origins of ageism among older and younger adults. International Psychogeriatrics, 1(6), 1003-1014. https://doi.org/10.1017/S104161020999055X

Bodner, E., Palgi, Y., \& Kaveh, D. (2012). Does the relationship between affect complexity and self-esteem differ in young-old and old-old participants? Journals of Gerontology Series B: Psychological Sciences and Social Sciences, 68(5), 665-673. https://doi.org/10.1093/geronb/ gbs095 
Bojner-Horwitz, E. (2018). Humanizing the working environment in health care through music and movement. In L. O. Bonde \& T. Theorell (Eds.), Music and public health: A Nordic perspective (pp. 187-199). Springer. https://doi.org/10.1007/978-3-319-76240-1_12

Bourdeau, B. (2000). Dual relationships in qualitative research. The Qualitative Report, 4(3), 1-6. Retrieved from http://nsuworks.nova.edu/tqr/vol4/iss3/7

Carstensen, L. L., Pasupathi, M., Mayr, U., \& Nesselroade, J. R. (2000). Emotional experience in everyday life across the adult life span. Journal of Personality and Social Psychology, 79(4), 644-655. https://psycnet.apa.org/doi/10.1037/0022-3514.79.4.644

Chiang, K. J., Chu, H., Chang, H. J., Chung, M. H., Chen, C. H., Chiou, H. Y., \& Chou, K. R. (2010). The effects of reminiscence therapy on psychological well-being, depression, and loneliness among the institutionalized aged. International Journal of Geriatric Psychiatry: A Journal of the Psychiatry of Late Life and Allied Sciences, 25(4), 380-388. https://doi.org/ 10.1002/gps.2350

Clair, A., \& Memmott, J. (2008). Therapeutic uses of music with older adults. American Music Therapy Association.

Clements-Cortés, A. (2017). Artful wellness: Attending a chamber music concert reduces pain and increases mood and energy for older adults. The Arts in Psychotherapy, 52, 41-49. https://doi.org/10.1016/j.aip.2016.10.001

Coffman, D. D. (2002). Music and quality of life in older adults. Psychomusicology: A Journal of Research in Music Cognition, 18(1-2), 76-88. https://doi.org/10.1037/h0094050

Cohen, G. D., Perlstein, S., Chapline, J., Kelly, J., Firth, K. M., \& Simmens, S. (2007). The impact of professionally conducted cultural programs on the physical health, mental health, and social functioning of older adults: Two-year results. Journal of Aging, Humanities, and the Arts, 1, 5-22. https://doi.org/10.1080/19325610701410791

Conneeley, A. L. (2002). Methodological issues in qualitative research for the researcher/ practitioner. British Journal of Occupational Therapy, 65(4), 185-190. https://doi.org/ 10.1177\%2F030802260206500406

Courtin, E., \& Knapp, M. (2017). Social isolation, loneliness, and health in old age: A scoping review. Health \& Social Care in the Community, 25(3), 799-812. https://doi.org/10.1111/ hsc. 12311

Creech, A., Hallam, S., McQueen, H., \& Varvarigou, M. (2013). The power of music in the lives of older adults. Research Studies in Music Education, 35, 87-102. https://doi.org/10.1177/ $1321103 X 13478862$

Dassa, A. (2018). Musical Auto-Biography Interview (MABI) as promoting self-identity and well-being in the elderly through music and reminiscence. Nordic Journal of Music Therapy, 27(5), 419-430. https://doi.org/10.1080/08098131.2018.1490921

DeNora, T. (2000). Music in everyday life. Cambridge University Press. https://doi.org/ 10.1017/CBO9780511489433

DuBois, D. L., Flay, B. R., \& Fagen, M. C. (2009). Self-esteem enhancement theory: Promoting health across the lifespan. In R. J. DiClemente, R. A. Crosby, \& M. C. Kegler (Eds.), Emerging theories in health promotion practice and research (pp. 97-130). Jossey-Bass/Wiley.

Ermer, A. E., York, K., \& Mauro, K. (2021). Addressing agism using intergenerational performing arts interventions. Gerontology \& Geriatrics Education, 42(3), 308-315.

Finnegan, R. (2012). Music, experience and the anthropology of emotion. In M. Clayton, T. Herbert, \& R. Middleton (Eds.), The cultural study of music: A critical introduction (pp. 181-192). Routledge.

Gabrielsson, A. (2002). Old people's remembrance of strong experiences related to music. Psychomusicology: A Journal of Research in Music Cognition, 18(1-2), 103-122. https://doi.org/10.1037/h0094048

Hays, T., \& Minichiello, V. (2005). The meaning of music in the lives of older people: A qualitative study. Psychology of Music, 33, 437-451. https://doi.org/10.1177/ 0305735605056160 
Harter, S. (2006). The development of self-esteem. In M. H. Kernis (Ed.), Self-esteem issues and answers: A sourcebook of current perspectives (pp. 144-150). Psychology Press.

Jackson, D. A. (2016). Exploring aging masculinities: The body, sexuality and social lives. Palgrave Macmillan.

Johnson, M. (2007). The meaning of the body: Aesthetics of human understanding. University of Chicago Press. https://doi.org/10.7208/chicago/9780226026992.001.0001

Juslin, P. N., \& Sloboda, J. A. (2010). The past, present, and future of music and emotion research. In P. N. Juslin, \& J. A. Sloboda (Eds.), Handbook of music and emotion: Theory, research, applications (pp. 933-955). Oxford University Press.

Kobau, R., Seligman, M. E., Peterson, C., Diener, E., Zack, M. M., Chapman, D., \& Thompson, W. (2011). Mental health promotion in public health: Perspectives and strategies from positive psychology. American Journal of Public Health, 101(8), e1-e9. https://doi.org/ 10.2105/AJPH.2010.300083

Kenny, C. (2014). The field of play: An ecology of being in music therapy. Voices: A World Forum for Music Therapy, 14(1). https://doi.org/10.15845/voices.v14i1.737

Kohlbacher, F. (2005). The use of qualitative content analysis in case study research. Forum: Qualitative Social Research, 7(1). https://doi.org/10.17169/fqs-7.1.75

Krok, D. (2015). The role of meaning in life within the relations of religious coping and psychological well-being. Journal of Religion and Health, 54(6), 2292-2308. https://doi.org/ 10.1007/s10943-014-9983-3

Levy, B. (2009). Stereotype embodiment: A psychosocial approach to aging. Current Directions in Psychological Science, 18(6), 332-336. https://doi.org/10.1111/j.1467-8721.2009.01662.x

Lindblad, K., \& de Boise, S. (2019). Musical engagement and subjective wellbeing amongst men in the third age. Nordic Journal of Music Therapy, 29(1), 1-19. https://doi.org/10.1080/ 08098131.2019.1646791

Loewy, J. (2004, March). Integrating music, language and the voice in music therapy. Voices: A World Forum for Music Therapy, 4(1). https://doi.org/10.15845/voices.v4i1.140

MacDonald, R. A. R., Hargreaves, D. J., \& Miell, D. (2002). What are musical identities, and why are they important? In R. A. R. MacDonald, D. J. Hargreaves, \& D. Miell (Eds.), Musical identities (pp. 1-20). Oxford University Press.

MacIntosh, H. B. (2003). Sounds of healing: Music in group work with survivors of sexual abuse. The Arts in Psychotherapy, 30(1), 17-23. https://doi.org/10.1016/

S0197-4556(02)00229-0

Mann, M. M., Hosman, C. M., Schaalma, H. P., \& De Vries, N. K. (2004). Self-esteem in a broad-spectrum approach for mental health promotion. Health Education Research, 19(4), 357-372. https://doi.org/10.1093/her/cyg041

Marchand, D. L. P., \& Bonamigo, A. W. (2015). Voice speech therapy in the aged: Exploratory systematic review of literature. Distúrbios Comun, 27(2), 309-17.

Mohammadi, A. Z., Shahabi, T., \& Panah, F. M. (2011). An evaluation of the effect of group music therapy on stress, anxiety, and depression levels in nursing home residents. Canadian Journal of Music Therapy, 17, 55-68.

Newham, P. (1998). Therapeutic voicework: Principles and practice for the use of singing as a therapy. Jessica Kingsley Publishers.

Noice, T., Noice, H., \& Kramer, A. F. (2013). Participatory arts for older adults: A review of benefits and challenges. The Gerontologist, 54(5), 741-753. https://doi.org/10.1093/geront/ gnt138

Oddy, N. (2011). A field of vocal discovery. In F. Baker \& S. Uhlig (Eds.), Voicework in music therapy: Research and practice (pp. 83-99). Jessica Kingsley Publishers.

O'Loughlin, P. (1995). Meetings with the unsounded voice. In C.B. Kenny (Ed.), Listening, playing, creating: Essays on the power of sound (pp. 161-175). State University of New York Press. 
Ong, A. D., \& Bergeman, C. S. (2004). The complexity of emotions in later life. The Journals of Gerontology Series B: Psychological Sciences and Social Sciences, 59(3), P117-P122. https://doi.org/10.1093/geronb/59.3.P117

Park, C. L., \& Folkman, S. (1997). Meaning in the context of stress and coping. Review of General Psychology, 1(2), 115-144. https://doi.org/10.1037/1089-2680.1.2.115

Patel, N. K., Akkihebbalu, S., Espinoza, S. E., \& Chiodo, L. K. (2011). Perceptions of a community-based yoga intervention for older adults. Activities, Adaptation \& Aging, 35(2), 151-163. https://doi.org/10.1080/01924788.2011.574256

Ready, R. E., \& Robinson, M. D. (2008). Do older individuals adapt to their traits? Personality-emotion relations among younger and older adults. Journal of Research in Personality, 42(4), 1020-1030. https://doi.org/10.1016/j.jrp.2008.02.004

Ready, R. E., Robinson, M. D., \& Weinberger, M. (2006). Age differences in the organization of emotion knowledge: Effects involving valence and time frame. Psychology and Aging, 21(4), 726-736. https://psycnet.apa.org/doi/10.1037/0882-7974.21.4.726

Robertson, S., \& Monaghan, L. F. (2012). Embodied heterosexual masculinities, part 2: Foregrounding men's health and emotions. Sociology Compass, 6(2), 151-165. https://doi.org/10.1111/j.1751-9020.2011.00443.x

Rogers, C. R. (1961). On becoming a person. Houghton Mifflin.

Russell, R. (2004). Social networks among elderly men caregivers. The Journal of Men's Studies, 13(1), 121-142. https://doi.org/10.3149/jms.1301.121

Ruud, E. (2013). Can music serve as a "cultural immunogen"? An explorative study. International Journal of Qualitative Studies on Health and Well-being, 8(1), 1-12. https://doi.org/10.3402/qhw.v8i0.20597

Seidler, V. J. (2007). Masculinities, bodies, and emotional life. Men and Masculinities, 10(1), 9-21. https://doi.org/10.1177/1097184X07299636

Skingley, A., Clift, S., M., Coulton, S. P., \& Rodriguez, J. (2011). The effectiveness and costeffectiveness of a participative community singing programme as a health promotion initiative for older people: Protocol for a randomized controlled trial. BMC Public Health, 11, Article 142. https://doi.org/10.1186/1471-2458-11-142

Stige, B., Malterud, K., \& Midtgarden, T. (2009). Toward an agenda for evaluation of qualitative research. Qualitative Health Research, 19(10), 1504-1516. https://doi.org/ 10.1177/1049732309348501

Tamplin, J., Baker, F. A., Jones, B., Way, A., \& Lee, S. (2013). 'Stroke a Chord': The effect of singing in a community choir on mood and social engagement for people living with aphasia following a stroke. NeuroRehabilitation, 32(4), 929-941. https://doi.org/10.3233/ NRE-130916

Volgsten, U. (2012). The roots of music: Emotional expression, dialogue and affect attunement in the psychogenesis of music. Musicae Scientiae, 16(2), 200-216. https://doi.org/10.1177/ 1029864912440778

Volgsten, U., \& Pripp, O. (2016). Music, memory and affect attunement: Connecting Kurdish diaspora in Stockholm. Culture Unbound: Journal of Current Cultural Research, 8(2), 144-164. https://doi.org/10.3384/cu.2000.1525.1608144

World Health Organization. (2017). Mental health of older adults [Fact sheet]. Retrieved from https://www.who.int/news-room/fact-sheets/detail/mental-health-of-older-adults

Zarate, R. (2016). Clinical improvisation and its effect on anxiety: A multiple single subject design. The Arts in Psychotherapy, 48, 46-53. https://doi.org/10.1016/j.aip.2015.11.005

Zanini, C. R. de O., \& Leao, E. (2006). Therapeutic choir - A music therapist looks at the new millennium elderly. Voices: A World Forum for Music Therapy, 6(2). https://doi.org/ 10.15845 /voices.v6i2.249

Zika, S., \& Chamberlain, K. (1992). On the relation between meaning in life and psychological well-being. British Journal of Psychology, 83(1), 133-145. https://doi.org/10.1111/

j.2044-8295.1992.tb02429.x 